\title{
Métodos de exames por imagem utilizados no diagnóstico de desadaptação entre implante e componente protético: uma revisão de literatura
}

\author{
Imaging methods used in the diagnosis of misfits in the implant-abutment joint: a review
}

\begin{abstract}
Maria de Fátima Oliveira Monteiro de Castro, ${ }^{1}$ Mylla Hagg Coutinho,, ${ }^{1}$ Pollyana Darós, ${ }^{2}$ Vinícius Cavalcanti Carneiro, ${ }^{2}$ Sergio Lins de-Azevedo-Vaz ${ }^{1}$
'Departamento de Clínica Odontológica, Curso de Odontologia, Universidade Federal do Espírito Santo, Vitória, ES, Brasil

${ }^{2}$ Programa de Pós-graduação em Clínica Odontológica, Universidade Federal do Espírito Santo, Vitória, ES, Brasil

- Os autores declaram que não há conflito de interesse.

\section{Resumo}

Objetivo: discorrer acerca dos exames por imagem empregados no diagnóstico de desadaptação entre implante e componente protético. Material e Métodos: para compor esta revisão bibliográfica, foram utilizadas as bases de dados CAPES, Pubmed, Cochrane e Medline. Inicialmente, utilizou como critério de inclusão apenas periódicos de revisão de literatura, estudos clínicos e estudos in vitro com as palavras-chave utilizadas em português, com sinônimos em inglês: radiografia dentária, implantação dentária, prótese dentária, adaptação implante/componente protético. Resultados: quarenta e seis artigos foram resgatados com base na leitura dos resumos. Após a leitura completa, vinte e quatro artigos nos idiomas Português e Inglês publicados entre 1985 e 2016 foram mantidos e fizeram parte desta revisão. Conclusão: a técnica do paralelismo é a mais indicada, visto que variações no ângulo vertical do feixe de raios $\mathrm{X}$, a partir da posição ortogonal, podem ocultar desadaptações e gerar complicações clínicas, comprometendo o tratamento reabilitador.

Palavras-chave: Radiografia dentária; Implantação dentária; Prótese dentária; Adaptação implante/Componente protético.

\section{ABSTRACT}

Objective: to discuss the imaging exams employed in the diagnosis of misfits in the implant-abutment joint. Material and Methods: the databases CAPES, Pubmed, Cochrane and Medline were used in this review. Initially, only periodicals of literature review, clinical studies and in vitro studies with the keywords used in Portuguese, with English synonyms were used: dental radiography, dental implant, dental prosthesis, implant abutment/misfit. Results: forty-six articles were retrieved based on the reading of the abstracts. After reading these articles, twenty-four articles in the Portuguese and English languages published between 1985 and 2016 were kept and were part of this review. Conclusion: periapical with standard paralleling technique is the most indicated, since variations in the vertical angle of the X-ray beam, from the orthogonal position can obscure misfits and generate clinical complications, compromising the rehabilitation treatment.

Keywords: Dental radiography; Dental implant; Dental prosthesis; Implant abutment/Misfit.
\end{abstract}

\section{Introdução}

$\mathbf{A}$ perda dentária é um problema que afeta a saúde do sistema estomatognático. Vários fatores podem acarretar a ocorrência desse problema. ${ }^{1}$ Segundo estudo realizado por Warren et al., ${ }^{2}$ os principais determinantes são cárie seguida da doença periodontal.

O componente protético é um pilar onde será adaptada a coroa que irá receber as cargas mastigatórias, transferindo -as ao implante. Ele é encaixado sobre os implantes através de uma conexão pré-estabelecida. Existem diversos tipos de conexões entre o implante e os componentes protéticos no mercado, contudo, há três tipos que são mais difundidos, são eles: conexões hexagonais externas (HE), hexagonais internas (HI) e o tipo cone morse (CM). ${ }^{3}$

Considerando que a localização subgengival da interface implante/componente protético dificulta a avaliação clínica, os exames por imagem - tal como a radiografia - tornam-se ferramentas imprescindíveis para a identificação de problemas nessa região, a exemplo das desadaptações. ${ }^{4,5}$

As radiografias periapicais são frequentemente utilizadas como método de avaliação de desadaptações na interface implante/componente protético. ${ }^{6}$ Whaites ${ }^{7}$ estabelece os requisitos necessários para a obtenção de radiografias periapi- cais geometricamente satisfatórias, isto é, com menor grau de distorção e magnificação. Dentre esses requisitos, destacam-se: 1) objeto (dente ou implante) e receptor de imagem (filme ou sensor radiográfico) devem estar em íntimo contato e em relação de paralelismo, 2) os feixes de raios X devem incidir perpendicularmente ao objeto e ao receptor de imagem. Todavia, a anatomia da cavidade bucal inviabiliza que esses requisitos ideais sejam atingidos, de forma que duas técnicas periapicais podem ser utilizadas, visando minimizar a distorção e magnificação na imagem radiográfica. São elas: técnica periapical da bissetriz e técnica periapical do paralelismo.

A técnica periapical da bissetriz - também conhecida como técnica da "isometria" - foi desenvolvida por Cieszynski, em 1907. Nessa técnica, o receptor de imagem é aproximado do objeto e os feixes centrais de raios X são orientados perpendicularmente ao plano bissetor virtual formado entre os planos longitudinais do objeto e do receptor de imagem, a fim de que a imagem radiográfica apresente as mesmas proporções da estrutura radiografada. ${ }^{8}$ Segundo White \& Pharoah, ${ }^{9}$ o ângulo vertical que direciona os raios centrais perpendicularmente ao plano bissetor varia com a anatomia de cada região. Em vista disso, várias medidas de ângulos 
podem ser usadas de acordo com a região a ser radiografada, mantendo-se o plano oclusal orientado paralelamente ao plano horizontal (Tabela 1). A técnica da bissetriz também pode ser realizada com o auxílio de posicionadores radiográficos que determinam a angulação vertical dos feixes de raios $\mathrm{X}$ a ser utilizada, de forma que os feixes centrais incidam perpendicularmente ao plano bissetor virtual. Nessa técnica, a aproximação do receptor de imagem em relação ao objeto visa reduzir as magnificações, inviabilizando, porém, uma relação de paralelismo entre ambos.

Tabela 1. Guia de angulações para as projeções em ângulo bissetor

\begin{tabular}{c|c|c}
\hline Técnica & Superior & Inferior \\
\hline Incisivos & $+45 \mathrm{a}+50^{\circ}$ & $-15 \mathrm{a}-20^{\circ}$ \\
\hline Caninos & $+40 \mathrm{a}+45^{\circ}$ & $-10 \mathrm{a}-15^{\circ}$ \\
\hline Pré-molares & $+30 \mathrm{a}+40^{\circ}$ & $-5 \mathrm{a}-10^{\circ}$ \\
\hline Molares & $+20 \mathrm{a}+30^{\circ}$ & $0 \mathrm{a}-5^{\circ}$ \\
\hline
\end{tabular}

$\mathrm{Na}$ técnica periapical do paralelismo - também conhecida como técnica do "cone longo" - há o emprego de posicionadores radiográficos específicos que distanciam o receptor de imagem do objeto, visando à manutenção de ambos em relação de paralelismo (Figuras 1 e 2). A técnica do paralelismo possui a vantagem de minimizar as distorções produzidas pelas diferenças geométricas na angulação entre o receptor de imagem e o objeto a ser radiografado, mantendo -os em relação de paralelismo. ${ }^{8}$ Contudo, há um consequente aumento da distância entre receptor de imagem e objeto.
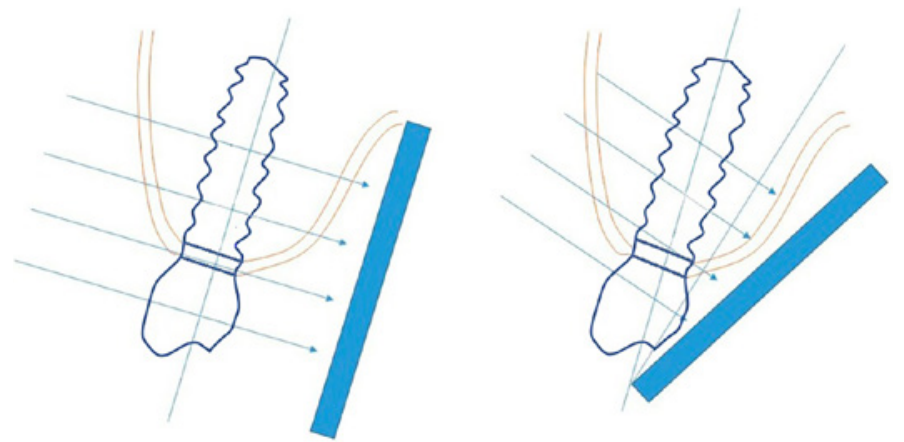

Figura 1. Esquema representativo: técnica do paralelismo e técnica da bissetriz. Esquerda - Técnica do paralelismo. Raios centrais direcionados perpendicularmente ao plano central do objeto e do filme. Direita - Técnica da bissetriz. Raios centrais direcionados perpendicularmente ao plano bissetor virtual do ângulo formado pelo receptor e pelo plano central do objeto
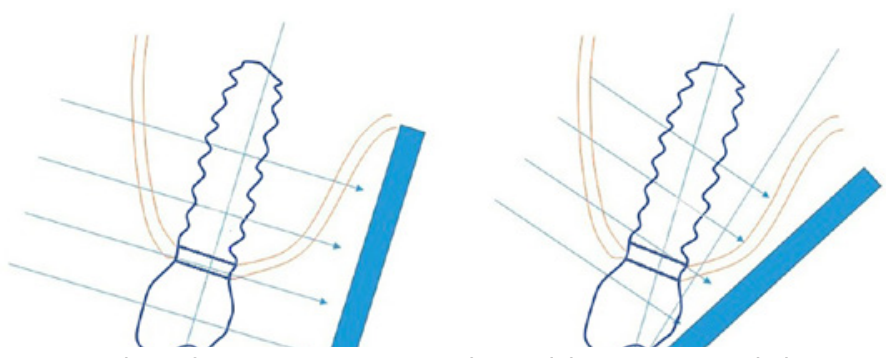

Figura 2. Radiografias periapicais: técnica do paralelismo e técnica da bissetriz. A - Técnica do paralelismo. Observe as espiras do implante bem definidas em consequência de raios ortogonais. B - Técnica da Bissetriz. Observe as espiras do implante sobrepostas
A literatura atualmente disponível $\mathrm{l}^{6,10-12}$ aponta que variações no ângulo vertical podem influenciar na capacidade de se detectar ou não desadaptações entre o implante e o componente protético. Portanto, aconselha-se que as radiografias com essa finalidade sejam feitas numa relação ortogonal (objeto e receptor paralelos entre si, feixes de raios $\mathrm{X}$ incidindo perpendicularmente a ambos). Contudo, Liedke et al. ${ }^{13}$ afirmam que as evidências que suportam o uso de exames por imagem na avaliação de desadaptações em próteses dentárias e restaurações se limita a estudos de baixa a moderada qualidade e que a técnica periapical do paralelismo ainda se encontra sob investigação. Assim, o presente estudo tem como objetivos discorrer acerca dos exames por imagem empregados no diagnóstico de desadaptação entre implante e componente protético, assim como, abordar a influência da angulação vertical dos feixes de raios $\mathrm{X}$ na identificação de desadaptação na interface implante/componente protético e discutir sobre a influência do grau de desadaptação na sua detecção radiográfica.

\section{Material e Métodos}

Para compor esta revisão bibliográfica, foi realizada uma busca eletrônica de artigos relevantes utilizando as bases de dados CAPES, Pubmed, Cochrane e Medline até junho de 2016. Inicialmente, utilizou como critério de inclusão apenas publicações de revisão de literatura, estudos clínicos e estudos in vitro com as palavras-chave utilizadas em português, com sinônimos em inglês: radiografia dentária, implantação dentária, prótese dentária, adaptação implante/componente protético. Foram excluídas as publicações que não eram pesquisas que contemplavam métodos de diagnóstico de desadaptações entre implante e componente protético e artigos que não condiziam com as línguas portuguesa e inglesa.

\section{Resultados}

A seleção das publicações foi feita em duas etapas: leitura do resumo e leitura integral das publicações. Após a pesquisa nas bases de dados, quarenta e seis publicações foram resgatadas com base na leitura dos resumos. Após a leitura completa, vinte e quatro artigos nos idiomas Português e Inglês publicados entre 1985 e 2016 foram mantidos e fizeram parte desta revisão.

\section{Discussão}

A perfeita adaptação do componente protético sobre o implante não pode ser negligenciada pelo profissional no momento da instalação da prótese, pois estudos mostram que gaps entre implante e componente protético podem levar ao insucesso do tratamento. Segundo alguns estudos, ${ }^{14-16}$ ta adaptação passiva do sistema é essencial para a integridade da saúde peri-implantar, pois desadaptações na interface implante/componente protético predispõem ao acúmulo 
de biofilme. A presença de biofilme bacteriano nessa região pode levar ao desenvolvimento de estados biológicos não desejáveis, tais como a inflamação dos tecidos peri-implantares e subsequente perda óssea ao redor do implante.

Embora o ideal seja uma adaptação perfeita, ou seja, livre de gaps, estudos apontam que microscopicamente é sempre esperado certo grau de desadaptação na interface implante/componente protético. ${ }^{17,18}$ Nesse sentido, alguns autores arriscaram definir um nível clinicamente tolerável dessa desadaptação, o qual não gere respostas biomecânicas indesejáveis. De acordo com Hecker e Eckert ${ }^{19}$ e Sousa et al. ${ }^{20}$ Brånemark foi o primeiro a definir a adaptação passiva, propondo que deveria existir um nível de desadaptação não superior a $10 \mu \mathrm{m}$ para permitir a maturação e remodelação óssea em resposta às forças oclusais. Já Klineberg e Murray ${ }^{21}$ sugeriam que desadaptações superiores a $30 \mu \mathrm{m}$ em mais de $10 \%$ da circunferência da interface implante/componente protético eram inaceitáveis. No entanto, Jemt e Book ${ }^{22}$ indicaram que desadaptações médias de $91 \mu \mathrm{m}$ e $111 \mu \mathrm{m}$ não causaram perda óssea ao redor dos implantes, considerando um nível aceitável de adaptação passiva. Nota-se que os autores não são consensuais em relação a este ponto, fato identificado por Benic, Elmasry e Hammerle, ${ }^{23}$ ao afirmarem que, embora haja correlação entre quantidade de desajuste e ocorrência de complicações técnicas, atualmente não se conhece o grau máximo de desajuste isento de posteriores complicações clínicas.

Buscando conhecer se há diferença entre os implantes HE e HI em relação à presença de gaps, localizou-se o estudo de Oliveira et al..$^{18}$ Os autores realizaram uma pesquisa em que foi usada a microscopia eletrônica de varredura a fim de identificar microespaços na interface implante/componente protético de quatro marcas comerciais nacionais de implantes dos tipos HE e HI. Concluiu-se que os dois sistemas apresentaram falhas na adaptação que são inerentes ao processo de fabricação e, assim, cabe ao cirurgião-dentista trabalhar com perícia para que essa falha não seja ampliada na técnica clínica.

A visualização da adaptação passiva da interface implante/componente protético não pode ser limitada a exames clínicos através da sondagem por se tratar de movimentos grosseiros realizados com as mãos e, portanto, não ser possível sentir a correta adaptação. Além disso, o instrumento utilizado, sonda clínica, possui dimensões elevadas para a avaliação de possíveis defeitos diminutos que podem ser encontrados na interface implante/componente protético. Por tal fato, é indispensável que se lance mão de exames por imagem, tais como as radiografias periapicais, principalmente devido ao posicionamento normalmente subgengival dessa interface. Konermann et al. ${ }^{24}$ puderam comprovar esse fato em seu estudo in vitro, no qual criaram artificialmente desadaptações na interface implante/componente e realiza- ram radiografias periapicais em condições ortogonais. Os autores observaram que as desadaptações foram significativamente mais detectadas pelo exame radiográfico do que pelo exame clínico. Adicionalmente, concluíram que quanto maior a magnitude de desadaptação, tanto menor é a dificuldade na sua visualização radiográfica.

Rotineiramente, observa-se que os clínicos têm lançado mão da radiografia periapical no momento da instalação da prótese utilizando o posicionador radiográfico modelo Han-shin, ou mesmo o fazem sem o auxílio de posicionadores. Ressalta-se que esses dispositivos são indicados para produzir radiografias segundo a técnica da bissetriz e que estudos já demonstraram diferenças na acurácia de diagnóstico. ${ }^{25}$

Cameron et al. ${ }^{11}$ constataram que desadaptações entre implante e componente protético somente puderam ser identificadas radiograficamente quando a variação do ângulo vertical do cabeçote de raios X era inferior a $20^{\circ}$. Ormaechea, Millstein e Hirayama ${ }^{10}$ concluíram que angulações verticais dos feixes de raios $\mathrm{X}$ de até $5^{\circ}$ permitiam a detecção de desadaptações de até $50 \mu \mathrm{m}$, e $10^{\circ}$ para desadaptações de até $150 \mu \mathrm{m}$. Já, no estudo de Sharkey et al., ${ }^{6}$ desadaptações tão pequenas quanto $12,7 \mu \mathrm{m}$ puderam ser detectadas em radiografias realizadas com o ângulo vertical de até $5^{\circ}$ a partir da posição ortogonal; e $51 \mu \mathrm{m}$ quando esse ângulo não fosse superior a $15^{\circ}$. No entanto, quando a angulação vertical foi igual ou superior a $20^{\circ}$, nenhuma desadaptação pôde ser detectada.

Portanto, quanto mais próximo da posição ortogonal, mais fiel será a imagem obtida do objeto em questão, e angulações superiores a $5^{\circ}$ impossibilitam o diagnóstico correto de possíveis desadaptações de cerca de $10 \mu \mathrm{m}$. Se considerarmos Hecker e Eckert ${ }^{19}$ e Sousa et al., ${ }^{20}$ esse nível de desadaptação já é clinicamente inaceitável. Mas para Jemt e Book, ${ }^{22}$ que tolera desadaptações de até $111 \mu \mathrm{m}$, variações no ângulo vertical de até $15^{\circ}$, apesar de ocultarem desadaptações tão importantes quanto as superiores $51 \mu \mathrm{m}$, podem ser toleradas. No entanto, a partir de $20^{\circ}$ considera-se que desadaptações de grande importância não serão detectadas, podendo levar a complicações clínicas, comprometendo o tratamento reabilitador. Sendo assim, ao se utilizar a técnica da bissetriz na região inferior - ângulo vertical médio de $0^{\circ}$ a $-20^{\circ}$, de posterior para anterior ${ }^{9}$ - trabalha-se no limite de angulação permitida para que desadaptações na interface implante/componente protético possam ser detectadas radiograficamente. Contudo, o seu uso teoricamente é inviável na região superior, onde se preconiza uma angulação vertical que varia de $+20^{\circ}$ a $+50^{\circ}$, de posterior para anterior. ${ }^{8}$

É importante salientar que todos os estudos analisados realizaram pesquisas em condições laboratoriais, não tendo, portanto, as limitações clínicas dadas pelas condições anatômicas variadas de cada paciente, as quais tornam a obtenção de radiografias ortogonais ainda mais crítica. Portanto, 
fica o alerta para que se busquem ferramentas que possibilitem tornar a técnica mais próxima da posição ortogonal, tal como o posicionador PIXRL desenvolvido por Lin et al. ${ }^{26}$

Dentre outros métodos de exame por imagem, a OCT (Tomografia por Coerência Óptica), estudada por Kikuchi et al., ${ }^{27}$ promete ser precisa na detecção dessas desadaptações. Entretanto, até o momento, esse método tem sua aplicação limitada a regiões onde a espessura de mucosa não seja superior a $1 \mathrm{~mm}$ para a obtenção de um diagnóstico preciso. Adicionalmente, possui a vantagem de ser um método livre de radiação ionizante.

\section{Conclusão}

Quando analisados microscopicamente, todos os sistemas de implante com conexão HE e HI apresentam certo grau de desadaptação. Portanto, é fundamental lançar mão de exames por imagens no momento da instalação do componente protético, de forma que esse gap seja apenas aquele advindo do processo de fabricação e não seja ampliado pela falta de perícia clínica.
Dentre as modalidades de exames por imagens atualmente disponíveis, as radiografias periapicais representam o método mais comumente utilizado clinicamente para a verificação da adaptação implante/componente protético. Contudo, elas devem ser realizadas na condição ortogonal (técnica do paralelismo) para que se tenha fidelidade da imagem radiográfica obtida.

A variação da angulação vertical do feixe de raios $\mathrm{X}$ é diretamente proporcional ao grau de dificuldade em se detectar as desadaptações. O oposto pôde ser observado com relação à magnitude das desadaptações, ou seja, quanto maior a desadaptação, menor a dificuldade em detectá-la. Contudo, gaps clinicamente importantes podem ser negligenciados quando essa angulação ultrapassa $15^{\circ}$ ou $20^{\circ}$.

A OCT mostrou-se um método de exame por imagem promissor para a identificação de desadaptação na interface implante/componente protético. Porém apresenta a limitação da espessura gengival, que deve ser inferior a $1 \mathrm{~mm}$ para um diagnóstico preciso.

\section{Referências}

1. De Marchi RJ, Leal AF, Padilha DM, Brondani MA. Vulnerability and the psychosocial aspects of tooth loss in old age: a southern brazilian study. J Cross Cult Gerontol. 2012;27(1):239-58.

2. Warren JJ, Watkins CA, Cowen HJ, Hand JS, Levy SM, Kuthy RA. Tooth loss in the very old: 13-15 year incidence among elderly Iowans. Community Dent Oral Epidemiol. 2002;30(1):29-37.

3. Rocha PV, Oliva EA, Pace N. Componentes protéticos sobre implante In: Rocha PV. et al. Todos os Passos da Prótese sobre Implante. Do planejamento ao controle posterior. 5. ed. São Paulo: Napoleão Editora; 2012. p. 156-8.

4. Broggini N. et al. Peri-implant inflammation defined by the implant-abutment interface. J Dent Res. 2006;85(5):473-8.

5. Todescan S, Lavigne S, Kelekis-Cholakis A. Guidance for the maintenance care of dental implantes: clinical review. J Can Dent Assoc. 2012;78(1):107.

6. Sharkey S, Kelly A, Houston F, O’Sullivan M, Quinn F, O’Connell B. A radiographic analysis of implant component misfit.

Int J Oral Maxillofac Implants. 2011;26(4):807-15.

7. Whaites E. Radiografia periapical. In: Whaites E. Princípios de Radiologia Odontológica. 4. ed. São Paulo: Elsevier; 2009. p. 81-5

8. Freitas A, Varoli OJ, Torres FA. Técnicas radiograficas intrabucais. In: Freitas A., Rosa JE, Souza IF. Radiologia Odontológica. 5. ed. São Paulo: Artes Médicas; 2000. p. 105.

9. White SC, Pharoah MJ. Exames radiográficos intra-orais. In: White SC, Pharoah, MJ. Radiologia Oral: Fundamentos e Interpretação. Rio de Janairo: Elsevier; 2007. p. 123-4.

10. Ormaechea BM, Millstein P, Hirayama H. Tube angulation effect on radiographic analysis of the implant-abutment interface. Int J Oral Maxillofac Implants. 2011;14(1):77-85.

11. Cameron SM, Joyce A, Brousseau JS, Parker MH. Radiographic verification of implant abutment seating. J Prosthet Dent. 1998;79(3):298-303.

12. Papavassiliou H, Kourtis S, Katerelou J, Chronopoulos V. Radiographical evaluation of the gap at the implant-abutment interface. J Esthet Restor Dent. 2010;22(4):235-50.

13. Liedke GS, Spin-Neto R, da Silveira HE, Wenzel A. Radiographic diagnosis of dental restoration misfit: a systematic review. J Oral Rehabil. 2015;41(12):9579675.

14. Aguirre-Zorzano LA, Estefanía-Fresco R, Telletxea O, Bravo M.Prevalence of peri-implant inflammatory disease in patients with a history of periodontal disease who receive supportive periodontal therapy. Clin Oral Implants Res.
2014;6(7):1-7.

15. Atieh MA, Alsabeeha NH, Faggion CM Jr, Duncan WJ. The Frequency of Peri-Implant Diseases: A Systematic Review and Meta-Analysis. J Periodontol. 2012;84(11):1-15.

16. Olmedo-Gaya MV, Manzano-Moreno FJ, Cañaveral-Cavero E, de Dios Luna-del Castillo J, Vallecillo-Capilla M. Risk factors associated with early implant failure: A 5-year retrospective clinical study. J Prosthet Dent. 2016;115(2):150-5. 17. Sahin S, Çehreli MC. The significance of passive framework fit in implant prosthodontics: current status. Implant Dent. 2001;10(2):85-92.

18. Oliveira GR, Olate S, Pozzer L, Cavalieri-Pereira L, Rodrigues-Chessa JG, Albergaría-Barbosa JR. Bacterial contamination along implant-abutment interface in external and internal-hex dental implants. Int J Clin Exp Med. 2014;7(3):580-5. 19. Hecker DM, Eckert SE. Cyclic loading of implant-supported prostheses: Changes in component fit over time. J Prosthet Dent. 2003;89(4):346-51.

20. Sousa BR, Nobre MA, Cavalheiro A, Borges J, Silva AL. Avaliação radiográfica de ajuste passivo em estruturas implanto-suportadas. Rev Port Estomatol Med Dent Cir Maxilofac. 2010;54(1):207-15.

21. Klineberg IJ, Murray GM. Design of superstructures for osseointegrated fixtures. Swed Dent J Suppl. 1985;28:63-9.

22. Jemt T, Book K. Prosthesis misfit and marginal bone loss in edentulous implant patients. Int J Oral Maxillofac Implants. 1996;11(5):620-5.

23. Benic GI, Eelmasry, M, Hammerle, CHF. Novel digital imaging techniques to assess the outcome in oral rehabilitation with dental implants: a narrative review. Clin Oral Impl Res. 2015;26(11):86-96.

24. Konermann AC, Zoellner A, Chang BM, Wright RF. In vitro study of the correlation between the simulated clinical and radiographic examination of microgaps at the implant-abutment interface. Quintessence Int. 2010;41(8):681-7.

25. Takeshita WM, Iwaki LCV, Da Silva MC, Tonin RH. Evaluation of diagnostic accuracy of conventional and digital periapical radiography, panoramic radiography, and cone-beam computed tomography in the assessment of alveolar bone loss. Contemp Clin Dent. 2014;5(3):318-23.

26. Lin KC, Wadhwani CP, Sharma A, Finzen F. A radiograph positioning technique to evaluate prosthetic misfit and bone loss around implants. J Prosthet Dent. 2014;111(1):163-5.

27. Kikuchi K, Akiba N, Sadr A, Sumi Y, Tagami J, Minakuchi S. Evaluation of the marginal fit at implant-abutment interface by optical coherence tomography. J Biomed Opt [internet]. 2014 May;19(5):055002. Disponível em: https://wwwncbi-nlm-nih-gov.ez43.periodicos.capes.gov.br/pubmed/24805806. 


\section{Mini Currículo e Contribuição dos Autores}

1. Maria de Fátima Oliveira Monteiro de Castro - cirurgiã-dentista. Contribuição: levantamento e interpretação dos dados.

2. Mylla Hagg Coutinho - cirurgiã-dentista. Contribuição: levantamento e interpretação dos dados.

3. Pollyana Darós - cirurgiã-dentista, MSc. Contribuição: interpretação de dados e redação do manuscrito.

4. Vinícius Cavalcanti Carneiro - cirurgião-dentista. Contribuição: redação do manuscrito e revisão crítica.

5. Sergio Lins de-Azevedo-Vaz - cirurgião-dentista, PhD. Contribuição: participação científica e intelectual, concepção e delineamento.

Recebido em: 03/04/2017 / Aprovado em: 04/06/2017

Autor Correspondente

Vinícius Cavalcanti Carneiro

E-mail: vinicius.cc@gmail.com 